\title{
CARCINOMA ESPINOCELULAR RETRO-MOLAR AVANÇADO: UM RELATO DE CASO
}

\author{
Sheezara Teles Lira dos Santos ${ }^{1}$, Samia Israele Braz do Nascimento ${ }^{1}$, Maxsuel Rolim da Costa ${ }^{2}$
}

Introdução: $O$ câncer de pele não melanoma é o mais comum no Brasil. Subdivide-se em Carcinoma Basocelular (CBC) e em Carcinoma Espinocelular (CEC). O CEC acomete mais homens e caucasianos. Seus principais fatores de risco são: exposição solar crônica, tabagismo, idade avançada e outros. O CEC tem natureza invasiva e pode evoluir com metástases para linfonodos regionais e órgãos distantes. Os fatores de proteção vão desde a diminuição da exposição solar às vestimentas e sombras artificiais. A conduta depende da localização anatômica, tempo de evolução e seu estadiamento, além das comorbidades que o paciente apresenta. Objetivo: Relatar um caso de uma paciente com Carcinoma Espinocelular retromolar avançado. Descrição do caso: Trata-se de uma paciente, E. J. F., 64 anos, sexo feminino, admitida na Unidade de Terapia Intensiva (UTI), proveniente do Centro Cirúrgico para Pelveglossomandibulectomia à direita ampliada para a Faringe, com Esvaziamento cervical radical ampliado à direita, Reconstrução com retalho de Peitoral Maior e Traqueostomia por Carcinoma Espinocelular (CEC) retro-molar avançado. $\mathrm{O}$ procedimento ocorreu sem intercorrências, sendo necessário realizar apenas dois concentrados de hemácias durante o ato cirúrgico. Pelo Exame Anatomo-Patológico de Congelação, o tumor de boca mede 2,6cm em seu maior eixo, infiltrando mandíbula e dente, e todas as margens cirúrgicas estão livres da neoplasia. É portadora de HAS (em uso regular de Losartana), sem outras patologias. É tabagista. Chega ao serviço de UTI ainda sob efeito residual da anestesia, consciente e orientada, hipocorada, em uso de $\mathrm{O}_{2}$ por Máscara de Venturi a $40 \%$, sem uso de drogas vasoativas e estável hemodinamicamente; com acesso venoso periférico em membro superior esquerdo, onde foi instalado hidratação venosa em BI; em dieta zero. Ferida operatória em região cervical e peitoral direito com curativo oclusivo aparentemente limpos e secos. Possui dreno de sucção dupla via em região cervical e peitoral direito com débito hemático presente apenas na região cervical. Em uso de Clindamicina e Ciprofloxacino. Evolui estável e aguarda alta da UTI. Conclusão: A ocorrência de câncer de pele ainda é uma realidade no Brasil, principalmente nos idosos. Estes têm mais agravantes, pois são portadores de sistema imune deficiente e sofreram as consequências dos fatores ambientais ao longo da vida. $\mathrm{O}$ conhecimento dos fatores de risco, além de medidas de proteção é fundamental para reduzir o índice de CEC.

Palavras-chave: Carcinoma Espinocelular, Câncer de pele não melanoma

\footnotetext{
${ }^{1}$ Acadêmica do $8^{\circ}$ semestre de Medicina da Faculdade de Medicina Estácio FMJ;

${ }^{2}$ Residente de Clínica Médica pela Estácio FMJ.

Autor correspondente: she.teles@ hotmail.com
}

47 Id on Line Rev. Mult. Psic. V.12, N. 40. 2018 - ISSN 1981-1179 EDIÇÃO ESPECIAL: I CURSO DE ONCOLOGIA DO CARIRI / II JORNADA DE PESQUISA QUANTI-QUALITATIVA EM ONCOLOGIA. JUAZEIRO DO NORTE, 05 A 10 DE MARÇO DE 2018. Edição eletrônica em http://idonline.emnuvens.com.br/id 